\title{
Hygroscopic Properties and Respiratory System Deposition Behavior of Particulate Matter Emitted By Mining and Smelting Operations
}

\author{
Jong-sang Youn ${ }^{1}$, Janae Csavina ${ }^{2}$, Kyle P. Rine ${ }^{3}$, Taylor Shingler ${ }^{4}$, Mark Patrick Taylor ${ }^{5}$, A. \\ Eduardo Sáez ${ }^{4}$, Eric A. Betterton ${ }^{3}$, and Armin Sorooshian $1,3,4,{ }^{*}$ \\ ${ }^{1} \mathrm{Mel}$ and Enid Zuckerman College of Public Health, University of Arizona, Tucson, AZ, USA \\ ${ }^{2}$ National Ecological Observatory Network (NEON), $168538^{\text {th }}$ Street, Boulder, CO USA \\ ${ }^{3}$ Department of Hydrology and Atmospheric Sciences, University of Arizona, Tucson, AZ, USA \\ ${ }^{4}$ Department of Chemical and Environmental Engineering, University of Arizona, Tucson, AZ, \\ USA \\ ${ }^{5}$ Department of Environmental Sciences, Macquarie University, North Ryde, Sydney, NSW 2109, \\ Australia
}

\section{Abstract}

This study examines size-resolved physicochemical data for particles sampled near mining and smelting operations and a background urban site in Arizona with a focus on how hygroscopic growth impacts particle deposition behavior. Particles with aerodynamic diameters between 0.056 $-18 \mu \mathrm{m}$ were collected at three sites: (i) an active smelter operation in Hayden, AZ, (ii) a legacy mining site with extensive mine tailings in Iron King, AZ, and (iii) an urban site, inner-city Tucson, AZ. Mass size distributions of As and $\mathrm{Pb}$ exhibit bimodal profiles with a dominant peak between $0.32-0.56 \mu \mathrm{m}$ and a smaller mode in the coarse range ( $>3 \mu \mathrm{m}$ ). The hygroscopicity profile did not exhibit the same peaks owing to dependence on other chemical constituents. Submicrometer particles were generally more hygroscopic than super-micrometer ones at all three sites with finite water-uptake ability at all sites and particle sizes examined. Model calculations at a relative humidity of $99.5 \%$ reveal significant respiratory system particle deposition enhancements at sizes with the largest concentrations of toxic contaminants. Between dry diameters of 0.32 and $0.56 \mu \mathrm{m}$, for instance, ICRP and MPPD models predict deposition fraction enhancements of $171 \%-261 \%$ and $33 \%-63 \%$, respectively, at the three sites.

\section{Keywords}

Aerosol; MOUDI; Mining; Smelting; Dust; Hygroscopicity

*Corresponding author: Armin Sorooshian (armin@email.arizona.edu; Phone: (520) 626-5858; Fax: (520) 621-6048; Postal Address: PO BOX 210011, Tucson, Arizona, 85721, USA). 


\section{Introduction}

Aerosol particles have substantial effects on human health, air quality, climate and biogeochemical cycling of nutrients and contaminants. As arid and semi-arid regions cover approximately a third of the global land area, dust is the most abundant particle type on a mass basis that contributes to such effects ${ }^{1}$. The highest combination of both dust emission potential and contaminant concentration is at mining sites, where ore handling and processing operations, as well as mine tailings, contribute to the atmospheric load of metal and metalloid contaminants ${ }^{2-4}$. Respiratory disease caused by emitted aerosol and especially wind-blown dust from mining operations is a large concern in many regions ${ }^{2}$. As mining and smelting operations continue in areas with population growth, there are elevated concerns regarding the harmful effects of airborne aerosol on vulnerable populations that are susceptible to respiratory and cardiovascular illness, as well as developmental complications. The transport of trace contaminants via aerosol particles is spatially more extensive than transport by other means such as waterways, which is demonstrative of the large-scale implications of contaminant transport by aerosol particles ${ }^{2}$.

A representative natural laboratory to investigate aerosol properties from mining and smelting emissions and subsequent effects on living beings is the southwest region of North America. In particular, Arizona is of major concern due to (i) extensive past and present mining across the $s^{2} \mathrm{e}^{2}$, (ii) high emissions of dust and metal/metalloid contaminants, especially from mining and smelting ${ }^{5}$, and (iii) a rapidly growing population that contains two communities that are especially vulnerable to the effects of aerosol particles: a large number of retirees who suffer from respiratory and cardiovascular diseases; and also infants vulnerable to dust ingestion from contaminated surfaces. A study in the highly populated and important commercial centers, Tucson and Phoenix (populations over one and four million, respectively; U.S. Census Bureau, 2009) reported higher metal and metalloid concentrations in dust ${ }^{6}$. Measurements on the outskirts of these cities near mining operations have revealed high levels of toxic elements (e.g., $\mathrm{Pb}, \mathrm{As}, \mathrm{Cd}$ ) owing to condensation and coagulation of smelting vapors and wind-eroded dust from mine tailings ${ }^{7}$. As the dust particles can be transported downwind and serve as cloud condensation nuclei (CCN) and ice nuclei (IN), their associated trace metals and metalloids make their way into cloud and rain water ${ }^{8}$. Consequently, sources of toxic dust can affect regions distant from the source area and enter waterways.

While much attention is placed on chemical characterization of aerosol particles, less effort has focused on determining how the dry size of ambient particles changes upon inhalation in living beings as a result of the high relative humidities (RHs) in the human respiratory system. Respiratory system RH reaches near saturation in the lungs $(\sim 99.5 \%)^{9-13}$ and is more variable in the upper head airways owing to its sensitivity to RH of the inhaled air, health of the individual, and breathing rate ${ }^{14}$. Aerosol hygroscopicity is a property that quantifies the growth of particles owing to water vapor uptake at a specific $\mathrm{RH}$, with the magnitude of this growth dependent on chemical composition. Agreement between models predicting particle deposition in the human respiratory tract and experimental measurements improves after accounting for aerosol hygroscopicity in the calculations ${ }^{15-22}$. 
It is well established that coarse particles deposit most effectively in the upper respiratory tract due largely to inertial impaction, whereas fine particles $\left(D_{p}<2.5 \mu \mathrm{m}\right)$ better penetrate the extrathoracic, conducting, and pulmonary airways of the human body upon inhalation $^{23-25}$. When reaching the lungs, such particles can then be transported to the blood stream by macrophages while contaminants such as metals and metalloids can diffuse into the blood stream ${ }^{26-27}$.

The goal of this work is to report on the hygroscopic properties of particles emitted by mining and smelting operations in contrast to an urban background site in Arizona. Sizeresolved chemical and hygroscopic data are first reported. Subsequent discussion focuses on using those data in model calculations to quantify the impact of hygroscopicity on deposition behavior in the human respiratory tract.

\section{Experimental Methods}

\subsection{Field Sites}

Size-resolved aerosol samples were collected at three field sites in Arizona (Figure 1) including an active smelting site, a legacy mining site, and an urban background site removed from mining. The active site is comprised of open pit mine, copper concentrator, smelter, and tailings impoundment in the twin towns of Hayden-Winkelman (referred to as Hayden hereafter). This site is about $\sim 160 \mathrm{~km}$ southeast of Phoenix and $80 \mathrm{~km}$ northeast of Tucson. Ongoing activities at this site result in airborne particles containing toxic contaminants such as $\mathrm{Pb}, \mathrm{As}$, and $\mathrm{Cd}^{7,28}$. The inactive mine is the Iron King Mine and Humboldt Smelter Superfund (IK) site, which is still responsible for emissions of contaminated aerosol $^{29}$. This site is approximately $\sim 120 \mathrm{~km}$ north of Phoenix and $\sim 280 \mathrm{~km}$ northwest of Tucson. Iron King was active from the late 1800s until 1969 producing $\mathrm{Au}, \mathrm{Cu}$, $\mathrm{Pb}, \mathrm{Zn}$, and $\mathrm{Ag}$. Its resulting mine tailings pile covers approximately 62 ha near the town of Dewey-Humboldt, Arizona ${ }^{30}$. Urban background site measurements were conducted at the Tucson Aerosol Characterization Observatory (referred to as TACO), which is on top of a building ( $30 \mathrm{~m}$ AGL, $720 \mathrm{~m}$ ASL; $32.2299^{\circ} \mathrm{N}, 110.9538^{\circ} \mathrm{W}$ ) in inner city Tucson on the campus of the University of Arizona. Numerous studies have been conducted at this site with details provided elsewhere ${ }^{31-34}$.

\subsection{Field Measurements}

Sampling was conducted with a micro-orifice uniform deposit impactor (MOUDI, MSP Corporation $)^{35}$ with aerodynamic cut-point diameters of $0.056,0.1,0.18,0.32,0.56,1.0$, $1.8,3.2,5.6,10.0$, and $18.0 \mu \mathrm{m}$. Table 1 summarizes the number of MOUDI samples sets and other measurement details for the three measurement sites. Teflon filters were used for MOUDI sampling (PTFE membrane, $2 \mu \mathrm{m}$ pore, $46.2 \mathrm{~mm}$, Whatman). The chemical analysis procedure for samples collected at each site was the same. A portion of the filters was extracted in sealed glass vials with aqua regia and sonication at $80^{\circ} \mathrm{C}$ for $60 \mathrm{~min}$ followed by analysis with inductively coupled plasma mass spectrometry (ICP-MS; Agilent 7700 Series) for elemental analysis. A separate portion of the filters was extracted in sealed glass vials with milli-Q water and sonication at $30^{\circ} \mathrm{C}$ for 20 minutes for analysis with ion chromatography (IC; Thermo Scientific Dionex ICS - 2100 system) for anions and cations. 
The dual IC system includes AS11-HC $(2 \times 250 \mathrm{~mm})$ and CS12A $(2 \times 250 \mathrm{~mm})$ columns for anion and cation analysis, respectively, in addition to a $25-\mu \mathrm{L}$ injection loop. Anion IC analysis was conducted with a 38-min multi-step gradient with potassium hydroxide eluent ( $2 \mathrm{mM}$ to $5 \mathrm{mM}$ from 0 to $8 \mathrm{~min}, 5 \mathrm{mM}$ to $10 \mathrm{mM}$ from 8 to $20 \mathrm{~min}, 10 \mathrm{mM}$ from 20 to 25 min, $10 \mathrm{mM}$ to $18.67 \mathrm{mM}$ from 25 to $38 \mathrm{~min}$ ). Cation IC analysis was conducted with a 38min isocratic method with methanesulfonic acid eluent $(10 \mathrm{mM})$. The elements of interest from the ICP-MS analysis include $\mathrm{Pb}$, As, and $\mathrm{Cd}$, while species analyzed with IC included organic acids (acetate, formate, oxalate) and inorganic ions $\left(\mathrm{Cl}^{-}, \mathrm{NO}_{2}{ }^{-}, \mathrm{NO}_{3}{ }^{-}, \mathrm{SO}_{4}{ }^{2-}, \mathrm{Na}^{+}\right.$, $\left.\mathrm{NH}_{4}{ }^{+}, \mathrm{K}^{+}, \mathrm{Mg}^{2+}, \mathrm{Ca}^{2+}\right)$. Hereafter, organic mass fraction refers to the sum of the three organic acids relative to the total mass of species from IC.

Parts of the aqueous extracts were atomized to a Differential Aerosol Sizing and Hygroscopicity Spectrometer Probe (DASH-SP, Brechtel Manufacturing Inc.) ${ }^{36}$ for quantification of hygroscopic growth factors (GFs), which are the ratio of particle diameter at humidified conditions relative to dry conditions ( $<20 \% \mathrm{RH}$ in this study). Atomization was conducted with a constant-rate atomizer and a desiccant dryer (Brechtel Manufacturing Inc. Model 9200). Dried aerosol particles were fed to the DASH-SP, which was used to select the diameter mode of the resultant dry aerosol size distribution $(\sim 225 \mathrm{~nm}$ in this study). Blank samples with the same water used in extraction of field samples were also aerosolized to the DASH-SP to confirm the absence of any interferences associated with the atomization process. The DASH-SP is comprised of the following in order of the direction of flow: (i) aerosol dryer, (ii) aerosol charge neutralizer, (iii) differential mobility analyzer (DMA) for selection of particles at a fixed diameter based on their electrical mobility, (iv) diffusion-based humidifier to bring particles to equilibrium at a pre-selected RH, (v) optical particle counters (OPCs) that obtain the light-scattering distribution of both dry and humidified particles, in separate channels, to ultimately retrieve the final humidified diameter using a data processing algorithm ${ }^{37}$. The OPCs use diode lasers at a wavelength of $532 \mathrm{~nm}$ (World Star Technologies, Model TECGL-30). For these experiments, the preselected RHs used for humidification were $70 \%, 80 \%$, and $90 \%$. Details of the DASH-SP operation, data processing algorithm, and quality control procedures are summarized in past work ${ }^{36-38}$.

Since hygroscopic growth factors are a sensitive function of the RH that the humidified diameter is measured at, it is convenient to quantify a single parameter value for hygroscopicity that represents water uptake across all RHs. This allows all the measurements in these experiments at the three RHs to be directly intercompared and to be extrapolated to other RHs of interest such as at the high value in lungs that is hard to reach with hygroscopicity instruments ${ }^{39}$. Growth factor values, which are provided for each site and $\mathrm{RH}$ tested in the Supporting Information (Table S1), were converted into kappa ( $\kappa$ ) values using the approximation in Equation $1^{40}$ :

$$
[G F]^{3}=1+\kappa\left(\frac{\frac{R H}{100 \%}}{1-\frac{R H}{100 \%}}\right)
$$

Environ Sci Technol. Author manuscript; available in PMC 2016 November 01. 
Kappa is frequently reported by measurement studies and can range from 0 (i.e., $\mathrm{GF}=1$ ) for insoluble particles (e.g., $\mathrm{CaCO}_{3}$ ) that do not grow to $\sim 1.2$ for $\mathrm{NaCl}$ particles, which are highly hygroscopic and exhibit significant growth ${ }^{41}$.

\subsection{Aerosol Deposition Modeling}

Modeling of particle deposition in human airways currently is conducted with a variety of different models ranging in complexity ${ }^{42}$. Computational fluid dynamics (CFD)-based models are among the most complex models that previously were limited to the upper respiratory tract and generally less accurate than other models even though they can cover a wider range of parameters ${ }^{42}$. However, in recent years more data has been collected to validate CFD-based models and they can be used for whole lung studies ${ }^{43-44}$. On the simpler side are a variety of semi-empirical models that can provide accurate results within a narrow range of parameters. Here we use two models that fit into the latter and simpler category of whole-lung models to estimate the impact of hygroscopic growth, as measured with the DASH-SP, on particle deposition in the human respiratory system. The first model is the Multiple-Path Particle Dosimetry (MPPD, v2.1 ${ }^{45-46}$, which quantifies deposition of aerosol particles ranging in size from $10 \mathrm{~nm}$ up to $20 \mu \mathrm{m}$ for the entire lung and also regional sections (lobar, tracheobronchial, pulmonary, alveolar). Results from MPPD are compared with those from perhaps the most widely referenced whole-lung model, the International Commission on Radiological Protection (ICRP) model ${ }^{47}$. A key difference between the models that impacts results is that ICRP accounts for the inhalable fraction of particles, which is the fraction of particles in the original volume of air that enters the nose or mouth. Full details of ICRP and MPPD model calculations are provided in the Supporting Information. These two models have been used for various applications such as examining health effects of simple salts, purely organic aerosol, pathogenic bioaerosol, and emissions from biomass burning, indoor sources, cigarettes, welding, and vehicular traffic ${ }^{14,20,39,48-51}$.

\section{Results and Discussion}

\subsection{Contaminant Mass Size Distributions}

Mass size distributions of aerosol species are of importance owing to the dependence of particle deposition in human airways on particle size. Such distributions for contaminants such as $\mathrm{Pb}, \mathrm{As}$, and $\mathrm{Cd}$ are of special importance owing to their adverse effect on human health ${ }^{2}$. Data indicate that communities close to smelters and mine tailings, especially children, have elevated levels of $\mathrm{As}$ and $\mathrm{Pb}$ in their blood and urine, respectively, due to dust ingestion and inhalation ${ }^{52-59}$. Here we discuss the characteristic mass size distribution of these toxic species to isolate the dry diameter range of particles with the highest concentrations and thus potential for leading to adverse health effects.

Figure 2 summarizes MOUDI data for $\mathrm{Pb}, \mathrm{As}$, and $\mathrm{Cd}$ at two of the three measurement sites. Although not shown in Table 1, eight sample sets were collected at Hayden between August and September of 2009 for only chemical characterization purposes. For Tucson and Hayden, mass size distributions reveal a dominant concentration peak in the sub-micrometer range, specifically between aerodynamic diameters of $0.32-0.56 \mu \mathrm{m}$. A second, albeit smaller, concentration peak exists between 3.2-10 $\mu \mathrm{m}$. The exception to these profile 
patterns is that $\mathrm{Cd}$ in Tucson was more abundant in the coarse mode (peak between 3.2-5.6 $\mu \mathrm{m})$. The mass concentrations at Hayden are expectedly higher than Tucson owing to the elevated levels of contaminants emitted from the smelter site. It is further noted that the mass size distributions of these contaminants are similar for other seasons of the year at Hayden, but with higher concentrations generally in the winter months due to a shallower mixing layer ${ }^{7}$.

Csavina et al. ${ }^{7}$ previously characterized the composition of particles emitted by Hayden and concluded that the sub-micrometer mode for these species is due to condensation and coagulation of smelting vapors, whereas in the coarse mode these species stem from aeolian transported fugitive dust, including especially from tailings. Similar observations of toxic metals and metalloids being associated with dust have been observed in other regions such as Australia ${ }^{58}$. Although not shown in Figure 2, the same type of bimodal distribution with a peak in the sub- and super-micrometer modes has been observed at Hayden for crustal dust tracer species (e.g., Sc, Al, Fe) ${ }^{7,61}$. Measurements near Australian copper and lead smelters in Mount Isa (Queensland) and a lead smelter in Port Pirie (South Australia) revealed similar mass size distributions for $\mathrm{Pb}$ and $\mathrm{As}$ with a dominant mode in the sub-micrometer fraction and a second smaller mode in the coarse fraction ${ }^{62}$. This suggests that a general profile of these species exists across different regions with active smelters. It is likely that Iron King exhibits a similar profile in the coarse mode owing to coated dust; however, it is possible that the sub-micrometer mode is absent as there is no active smelter. The characteristic peaks observed in the sub- and super-micrometer ranges motivate a closer look at the hygroscopic profiles of the sampled aerosol.

\subsection{Size-Resolved Hygroscopicity Profile}

The aerosol at the three measurement sites expectedly displayed the ability to take up water vapor (i.e., GF $>1$ and $\kappa>0$ ) at all RHs examined with variability as a function of size and location (Figure 3$)$. The average ( \pm 1 standard deviation) $\kappa$ values were $0.12( \pm 0.05), 0.16$ $( \pm 0.06)$, and $0.07( \pm 0.03)$ for Hayden, Iron King, and TACO, respectively. Hayden aerosol were most hygroscopic in the sub-micrometer range $(\kappa: 0.12-0.18)$ with the peak value between $0.056-0.1 \mu \mathrm{m}$. In the super-micrometer range, $\kappa$ varied between $0.07-0.12$ with its lowest value between $10-18 \mu \mathrm{m}$. Iron King aerosol differed from Hayden in that the peak $\kappa(0.19)$ was highest between $0.56-1 \mu \mathrm{m}$, but similarly the lowest $\kappa(0.12)$ was between $10-18 \mu \mathrm{m}$. For TACO samples, $\kappa$ exhibited a maximum value for diameters between 0.32 - $0.56 \mu \mathrm{m}$ coinciding with the peak concentrations of $\mathrm{Pb}$ and As. Otherwise, $\kappa$ exhibited very little variability (0.054 - 0.064) at sizes below $0.1 \mu \mathrm{m}$ and above $1 \mu \mathrm{m}$. On average, the sub-micrometer stages at all sites exhibited a higher $\kappa$ as compared to supermicrometer sizes.

\subsection{Hygroscopicity and Composition Comparison}

While the focus of this study is mainly on the hygroscopicity measurements and their ultimate impacts on the particle deposition model predictions, $\boldsymbol{\kappa}$ values are still compared here to composition data. The goal is to see how well the measured constituent concentrations govern hygroscopic growth at a fixed RH. Previous work has shown that the relative amount of organic matter to ambient aerosol is a good predictor of hygroscopic 
growth $^{38}$ with the caveat that their results were for the marine boundary layer, which is characterized by different aerosol composition. A limitation of our study is that only a subset of all species in the ambient aerosol was measured, especially among the organic fraction of the aerosol.

The data show that there was low variability in inorganic mass fraction as a function of either dry diameter or location. For example, the cumulative stage-averaged inorganic mass fraction was $0.87( \pm 0.04), 0.91( \pm 0.04)$, and $0.87( \pm 0.05)$ for Hayden, Iron King, and Tucson, respectively. The most abundant constituent in the sub-micrometer range was sulfate at the three sites with stage-averaged mass fraction of 0.37, 0.36, and 0.44 for, Hayden, Iron King, and Tucson, respectively. The second most abundant sub-micrometer species was either sodium (Tucson), potassium (Hayden), or chloride (Iron King). The highest mass fraction in the super-micrometer range was for either sodium (Hayden: 0.26), chloride (Iron King: 0.31), or sulfate (Tucson: 0.21). Perhaps, the clearest signature of a relationship between $\mathrm{x}$ and the IC measurements in Figure 3 is for the sub-micrometer range at Tucson, which is the site with the highest relative contribution of sulfate to the overall mass.

Sulfate's highest mass fraction ( 0.56 ) between $0.32-0.56 \mu$ m exceeded the maximum mass fraction at the other sites (0.44-0.49), albeit not by a large margin. When sulfate's relative contribution decreases, a number of other species increase in their contribution, including nitrate, potassium, and calcium, which exhibited the greatest enhancement in mass fraction relative to other species above $1 \mu \mathrm{m}$ relative to below $1 \mu \mathrm{m}$ in Tucson.

While there is a lack of relationship between either organic or inorganic mass fraction with $x$ at a particular site, there is an improved relationship when combining data from the three sites. When examining sub- and super-micrometer diameters independently, $\mathrm{x}$ and organic mass fraction are inversely related with statistical significance at $95 \%$ confidence based on a student's t-test (Figure 4). Future measurements with more speciation can likely lead to an improved assessment of what chemical parameters best predict hygroscopicity at these sites.

\subsection{Particle Deposition Results}

The nature of how particles grow and deposit in the human respiratory system is complex and the subsequent discussion focuses on qualitative differences in predicted deposition behavior between dry MOUDI cut-point diameters and their associated humidified diameter after multiplication with measured hygroscopic GFs. While each MOUDI stage represents a range of diameters, we focus on the cut-point size when referring to each stage for simplicity. Since the RH experienced by inhaled particles can reach as high as $99-99.8 \%$ in the lungs ${ }^{9,63}$, we utilize measurement-based $\kappa$ values at $90 \%$ RH to derive growth factors at 99.5\% using Equation 1.

Figure 5 summarizes results for the three measurement sites using the ICRP and MPPD models, with numerical values provided in Table S2 (Supporting Information). Before GF adjustment, the total deposition fraction follows the well-documented curve with minimum values in the sub-micrometer range $(\sim 0.1-1.0 \mu \mathrm{m})$ owing to the enhanced diffusional losses for ultrafine particles $(<0.1 \mu \mathrm{m})$ in the alveolar regions and inertial impaction and settling above $1 \mu \mathrm{m}$. After hygroscopic growth size adjustment, the cut-point diameter exhibiting the greatest change in deposition fraction is $0.56 \mu \mathrm{m}$ with the ICRP model and $1 \mu \mathrm{m}$ with the 
MPPD model; other computational work has shown the greatest change in deposition fraction is for $1 \mu \mathrm{m}$ salt particles ${ }^{64}$. With regard to the highest concentration of $\mathrm{Pb}$ and $\mathrm{As}$, the cut-point diameter of $0.32 \mu \mathrm{m}$ is of significance in terms of how humidification impacts deposition. Of the two models, ICRP predicts the greatest percent enhancement of deposition: $261 \%$ at Iron King, 207\% at Hayden, $171 \%$ at Tucson. MPPD still predicts a considerable enhancement though: $63 \%$ at Iron King, $45 \%$ at Hayden, $33 \%$ at Tucson.

Figure 6 extends the analysis to specific regions of the respiratory tract including the Head Airway (HA), Tracheobronchial (TB), and Alveolar (AL) regions. Since impaction and settling are most efficient in the HA region, humidification has the effect of increasing deposition fraction for almost all cut-point diameters examined except the smallest one $(0.056 \mu \mathrm{m})$ when using both models, in addition to the two largest ones $(5.6 \mu \mathrm{m}$ and $10 \mu \mathrm{m})$ when using ICRP. In the TB region, humidification is shown the reduce deposition fraction for cut-point diameters $\leq 0.18$ and $\geq 1.8 \mu \mathrm{m}$ with ICRP, and $\leq 0.32 \mu \mathrm{m}$ and $\geq 5.6 \mu \mathrm{m}$ with MPPD. The AL results are qualitatively similar to TB with the exception that the aforementioned sizes are all shifted to the next smallest cut-point size.

The regionally-specific results have major implications for the deposition of particles enriched with toxic contaminants in the measurements regions. For example, if particles were inhaled instead of being collected in the 0.32-0.56 $\mu \mathrm{m}$ MOUDI stage, they would change in where they deposit after accounting for hygroscopic growth. Both $0.32 \mu \mathrm{m}$ and $0.56 \mu \mathrm{m}$ are the sizes exhibiting the greatest increase in deposition fraction in the AL region based on the ICRP model. In terms of extensions of this work, future analysis can extend such measurements to quantify lung doses at a given site for an average subject.

\section{Supplementary Material}

Refer to Web version on PubMed Central for supplementary material.

\section{Acknowledgements}

This work was funded by Grant 2 P42 ES04940 from the National Institute of Environmental Health Sciences (NIEHS) Superfund Research Program, NIH. TS was funded by the NASA Earth And Space Science Fellowship (NESSF) Program (NNX14AK79H).

Supporting Information Available: A table is provided to report all measured growth factors in this work, in addition to another table to complement Figure 5. Model calculations for ICRP and MPPD models are also summarized. This information is available free of charge via the Internet at http://pubs.acs.org.

\section{References}

1. Seinfeld, JH.; Pandis, SN. Atmospheric Chemistry and Physics. Third Edition. Wiley-Interscience; New York: 2016.

2. Csavina J, Field J, Taylor MP, Gao S, Landazuri A, Betterton EA, Saez AE. A review on the importance of metals and metalloids in atmospheric dust and aerosol from mining operations. Sci. Total Environ. 2012; 433:58-73. [PubMed: 22766428]

3. Taylor MP, Mould SA, Kristensen LJ, Rouillon M. Environmental arsenic, cadmium and lead dust emissions from metal mine operations: Implications for environmental management, monitoring and human health. Environ. Res. 2014a; 135:296-303. [PubMed: 25462679] 
4. Dong CY, Taylor MP, Kristensen LJ, Zahran S. Environmental contamination in an Australian mining community and potential influences on early childhood health and behavioural outcomes. Environ. Pollut. 2015; 207:345-356. [PubMed: 26448503]

5. Malm WC, Sisler JF. Spatial patterns of major aerosol species and selected heavy metals in the United States. Fuel Process Technol. 2000; 65:473-501.

6. Prabhakar G, Sorooshian A, Toffol E, Arellano AF, Betterton EA. Spatiotemporal distribution of airborne particulate metals and metalloids in a populated arid region. Atmos. Environ. 2014; 92:339-347.

7. Csavina J, Landazuri A, Wonaschutz A, Rine K, Rheinheimer P, Barbaris B, Conant W, Saez AE, Betterton EA. Metal and metalloid contaminants in atmospheric aerosols from mining operations. Water Air Soil Poll. 2011; 221(1-4):145-157.

8. Sorooshian A, Shingler T, Harpold A, Feagles CW, Meixner T, Brooks PD. Aerosol and precipitation chemistry in the southwestern United States: spatiotemporal trends and interrelationships. Atmos. Chem. Phys. 2013; 13(15):7361-7379. [PubMed: 24432030]

9. Anselm A, Heibel T, Gebhart J, Ferron G. Invivo studies of growth-factors of sodium-chloride particles in the human respiratory-tract. J. Aerosol Sci. 1990; 21:S427-S430.

10. Ferron GA, Haider B, Kreyling WG. A Method for the Approximation of the Relative-Humidity in the Upper Human Airways. B. Math Biol. 1985; 47(4):565-589.

11. Labiris NR, Dolovich MB. Pulmonary drug delivery. Part I: Physiological factors affecting therapeutic effectiveness of aerosolized medications. Brit.J. Clin. Pharmaco. 2003; 56(6):588-599.

12. Löndahl J, Pagels J, Swietlicki E, Zhou JC, Ketzel M, Massling A, Bohgard M. A set-up for field studies of respiratory tract deposition of fine and ultrafine particles in humans. J. Aerosol Sci. 2006; 37(9):1152-1163.

13. Löndahl J, Massling A, Pagels J, Swietlicki E, Vaclavik E, Loft S. Size-resolved respiratory-tract deposition of fine and ultrafine hydrophobic and hygroscopic aerosol particles during rest and exercise. Inhal. Toxicol. 2007; 19(2):109-116. [PubMed: 17169858]

14. Haddrell AE, Davies JF, Reid JP. Dynamics of particle size on inhalation of environmental aerosol and impact on deposition fraction. Environ. Sci. Technol. 2015; 49(24):14512-14521. [PubMed: 26568475]

15. Blanchard JD, Willeke K. Total deposition of ultrafine sodium-chloride particles in human lungs. J. Appl. Physiol. 1984; 57(6):1850-1856. [PubMed: 6511558]

16. Tu KW, Knutson EO. Total deposition of ultrafine hydrophobic and hygroscopic aerosols in the human respiratory system. Aerosol Sci. Tech. 1984; 3(4):453-465.

17. Broday DM, Georgopoulos PG. Growth and deposition of hygroscopic particulate matter in the human lungs. Aerosol Sci. Tech. 2001; 34(1):144-159.

18. Schroeter JD, Musante CJ, Hwang DM, Burton R, Guilmette R, Martonen TB. Hygroscopic growth and deposition of inhaled secondary cigarette smoke in human nasal pathways. Aerosol Sci. Tech. 2001; 34(1):137-143.

19. Montoya LD, Lawrence J, Murthy GGK, Sarnat JA, Godleski JJ, Koutrakis P. Continuous measurements of ambient particle deposition in human subjects. Aerosol Sci. Tech. 2004; 38(10): 980-990.

20. Löndahl J, Massling A, Swietlicki E, Brauner EV, Ketzel M, Pagels J, Loft S. Experimentally determined human respiratory tract deposition of airborne particles at a busy street. Environ. Sci. Technol. 2009; 43(13):4659-4664. [PubMed: 19673248]

21. Hussein T, Löndahl J, Paasonen P, Koivisto AJ, Petaja T, Hameri K, Kulmala M. Modeling regional deposited dose of submicron aerosol particles. Sci. Total Environ. 2013; 458:140-149. [PubMed: 23644567]

22. Vu T, Delgado-Saborit J, Harrison R. A review of hygroscopic growth factors of submicron aerosols from different sources and its implication for calculation of lung deposition efficiency of ambient aerosols. Air Qual. Atmos. Hlth. 2015; 8(5):429-440.

23. Heyder J, Gebhart J, Rudolf G, Schiller CF, Stahlhofen W. Deposition of Particles in the Human Respiratory-Tract in the Size Range 0.005-15-Mu-M. J. Aerosol Sci. 1986; 17(5):811-825.

24. Schlesinger RB. Deposition and clearance of inhaled particles. Concepts in inhalation toxicology (Second Edition). 1995:191-224. 
25. Park SS, Wexler AS. Size-dependent deposition of particles in the human lung at steady-state breathing. J. Aerosol Sci. 2008; 39(3):266-276.

26. Krombach F, Munzing S, Allmeling AM, Gerlach JT, Behr J, Dorger M. Cell size of alveolar macrophages: An interspecies comparison. Environ. Health Persp. 1997; 105:1261-1263.

27. Valiulis D, Sakalys J, Plauskaite K. Heavy metal penetration into the human respiratory tract in vilnius. Lith. J. Phys. 2008; 48(4):349-355.

28. EPA ASARCO Hayden Superfund Site. 2008. http://yosemite.epa.gov/r9/sfund/r9sfdocw.nsf/ 7508188dd3c99a2a8825742600743735/3940634a9aec311e88257478006736ce!OpenDocument

29. EPA Iron King Mine Superfund Site. 2008. http://yosemite.epa.gov/r9/sfund/r9sfdocw.nsf/ 7508188dd3c99a2a8825742600743735/316161edfc4699a5882574ab0001d1c0!OpenDocument

30. Gil-Loaiza J, White SA, Root RA, Solis-Dominguez FA, Hammond CM, Chorover J, Maier RM. Phytostabilization of mine tailings using compost-assisted direct planting: Translating greenhouse results to the field. Sci. Total Environ. 2016; 565:451-461. [PubMed: 27183459]

31. Youn JS, Wang Z, Wonaschutz A, Arellano A, Betterton EA, Sorooshian A. Evidence of aqueous secondary organic aerosol formation from biogenic emissions in the North American Sonoran Desert. Geophys. Res. Lett. 2013; 40(13):3468-3472. [PubMed: 24115805]

32. Youn JS, Crosbie E, Maudlin LC, Wang Z, Sorooshian A. Dimethylamine as a major alkyl amine species in particles and cloud water: Observations in semi-arid and coastal regions. Atmos. Environ. 2015; 122:250-258.

33. Crosbie E, Youn JS, Balch B, Wonaschutz A, Shingler T, Wang Z, Conant WC, Betterton EA, Sorooshian A. On the competition among aerosol number, size and composition in predicting CCN variability: a multi-annual field study in an urbanized desert. Atmos. Chem. Phys. 2015; 15(12): 6943-6958. [PubMed: 26316879]

34. Sorooshian A, Crosbie E, Maudlin LC, Youn JS, Wang Z, Shingler T, Ortega AM, Hersey S, Woods RK. Surface and airborne measurements of organosulfur and methanesulfonate over the western United States and coastal areas. J. Geophys. Res. 2015; 120(16):8535-8548.

35. Marple VA, Rubow KL, Behm SM. A microorifice uniform deposit impactor (MOUDI) description, calibration, and Use. Aerosol Sci. Tech. 1991; 14(4):434-446.

36. Sorooshian A, Hersey S, Brechtel FJ, Corless A, Flagan RC, Seinfeld JH. Rapid, size-resolved aerosol hygroscopic growth measurements: Differential aerosol sizing and hygroscopicity spectrometer probe (DASH-SP). Aerosol Sci. Tech. 2008; 42(6):445-464.

37. Shingler T, Crosbie E, Ortega A, Shiraiwa M, Zuend A, Beyersdorf A, Ziemba L, Anderson B, Thornhill L, Perring AE, Schwarz JP, Campazano-Jost P, Day DA, Jimenez JL, Hair JW, Mikoviny T, Wisthaler A, Sorooshian A. Airborne characterization of subsaturated aerosol hygroscopicity and dry refractive index from the surface to $6.5 \mathrm{~km}$ during the SEAC ${ }^{4} \mathrm{RS}$ campaign. J. Geophys. Res. 2016; 121(8):4188-4210.

38. Hersey SP, Sorooshian A, Murphy SM, Flagan RC, Seinfeld JH. Aerosol hygroscopicity in the marine atmosphere: a closure study using high-time-resolution, multiple-RH DASH-SP and sizeresolved C-ToF-AMS data. Atmos. Chem. Phys. 2009; 9(7):2543-2554.

39. Kristensson A, Rissler J, Löndahl J, Johansson C, Swietlicki E. Size-resolved respiratory tract deposition of sub-micrometer aerosol particles in a residential area with wintertime wood combustion. Aerosol Air Qual. Res. 2013; 13(1):24-35.

40. Petters MD, Kreidenweis SM. A single parameter representation of hygroscopic growth and cloud condensation nucleus activity. Atmos. Chem. Phys. 2007; 7(8):1961-1971.

41. Kreidenweis, SM.; Asa-Awuku, A. 5.13 - Aerosol Hygroscopicity: Particle Water Content and Its Role in Atmospheric Processes. In: Turekian, HDHK., editor. Treatise on Geochemistry. Second Edition. Elsevier; Oxford: 2014. p. 331-361.

42. Rostami AA. Computational modeling of aerosol deposition in respiratory tract: a review. Inhal. Toxicol. 2009; 21(4):262-290. [PubMed: 19235608]

43. Tian G, Hindle M, Lee S, Longest PW. Validating CFD predictions of pharmaceutical aerosol deposition with in vivo data. Pharm. Res. 2015; 32(10):3170-3187. [PubMed: 25944585]

44. Kerekes A, Nagy A, Veres M, Rigo I, Farkas A, Czitrovszky A. In vitro and in silico (IVIS) flow characterization in an idealized human airway geometry using laser Doppler anemometry and computational fluid dynamics techniques. Measurement. 2016; 90:144-150. 
45. Anjilvel S, Asgharian B. A Multiple-Path Model of Particle Deposition in the rat lung. Fund. Appl. Toxicol. 1995; 28(1):41-50.

46. National Institute for Public Health and the Environment (RIVM). Multiple Path Particle Dosimetry Model (MPPD v 1.0): A model for human and rat airway particle dosimetry. Bilthoven, The Netherlands: 2002. RIVA Report 650010030

47. International Commission on Radiological Protection. Human respiratory tract model for radiological protection. Pergamon Press; Oxford, London: 1994. ICRP publication 66

48. Oravisjarvi K, Pietikainen M, Ruuskanen J, Rautio A, Voutilainen A, Keiski RL. Effects of physical activity on the deposition of traffic-related particles into the human lungs in silico. Sci. Total Environ. 2011; 409(21):4511-4518. [PubMed: 21871649]

49. Zhang YP, Sumner W, Chen DR. In vitro particle size distributions in electronic and conventional cigarette aerosols suggest comparable deposition patterns. Nicotine Tob. Res. 2013; 15(2):501508. [PubMed: 23042984]

50. Guha S, Hariharan P, Myers MR. Enhancement of ICRP's lung deposition model for pathogenic bioaerosols. Aerosol Sci. Tech. 2014; 48(12):1226-1235.

51. Manigrasso M, Guerriero E, Avino P. Ultrafine particles in residential indoors and doses deposited in the human respiratory system. Atmosphere. 2015; 6(10):1444-1461.

52. Baker EL, Hayes CG, Landrigan PJ, Handke JL, Leger RT, Housworth WJ, Harrington JM. Nationwide survey of heavy-metal absorption in children living near primary copper, lead, and zinc smelters. Am. J. Epidemiol. 1977; 106(4):261-273. [PubMed: 910795]

53. Wichmann HE, Trepka MJ, Heinrich J, Ihme W, Mekel O, Lin JH. From epidemiologic exposure and risk assessment to probabilistic models: Experience with the investigation of health effects of soil contamination in Germany. Int. J. Toxicol. 1997; 16(4-5):391-418.

54. Tong S, von Schirnding YE, Prapamontol T. Environmental lead exposure: a public health problem of global dimensions. B. World Health Organ. 2000; 78(9):1068-1077.

55. Needleman H. Lead poisoning. Annu. Rev. Med. 2004; 55:209-22. [PubMed: 14746518]

56. Munksgaard NC, Taylor MP, Mackay A. Recognising and responding to the obvious: the source of lead pollution at Mount Isa and the likely health impacts. Med. J. Australia. 2010; 193(3):131132. [PubMed: 20678035]

57. Taylor MP, Mackay AK, Hudson-Edwards KA, Holz E. Soil Cd, Cu, Pb and Zn contaminants around Mount Isa city, Queensland, Australia: Potential sources and risks to human health. Appl. Geochem. 2010; 25(6):841-855.

58. Taylor MP, Davies PJ, Kristensen LJ, Csavina JL. Licenced to pollute but not to poison: The ineffectiveness of regulatory authorities at protecting public health from atmospheric arsenic, lead and other contaminants resulting from mining and smelting operations. Aeolian Res. 2014b; 14:35-52.

59. Soto-Jimenez MF, Flegal AR. Childhood lead poisoning from the smelter in Torreon, Mexico. Environ. Res. 2011; 111(4):590-596. [PubMed: 21329917]

60. Laidlaw MAS, Zahran S, Pingitore N, Clague J, Devlin G, Taylor MP. Identification of lead sources in residential environments: Sydney Australia. Environ. Pollut. 2014; 184:238-246. [PubMed: 24071634]

61. Sorooshian A, Csavina J, Shingler T, Dey S, Brechtel FJ, Saez AE, Betterton EA. Hygroscopic and chemical properties of aerosols collected near a copper smelter: implications for public and environmental health. Environ. Sci. Technol. 2012; 46(17):9473-9480. [PubMed: 22852879]

62. Csavina J, Taylor MP, Felix O, Rine KP, Saez AE, Betterton EA. Size-resolved dust and aerosol contaminants associated with copper and lead smelting emissions: Implications for emission management and human health. Sci. Total Environ. 2014; 493:750-756. [PubMed: 24995641]

63. Byron PR, Davis SS, Bubb MD, Cooper P. Pharmaceutical implications of particle growth at high relative humidities. Pestic. Sci. 1977; 8(5):521-526.

64. Ferron GA, Kreyling WG, Haider B. Inhalation of salt aerosol-particles. 2. Growth and deposition in the human respiratory-tract. J. Aerosol Sci. 1988; 19(5):611-631. 


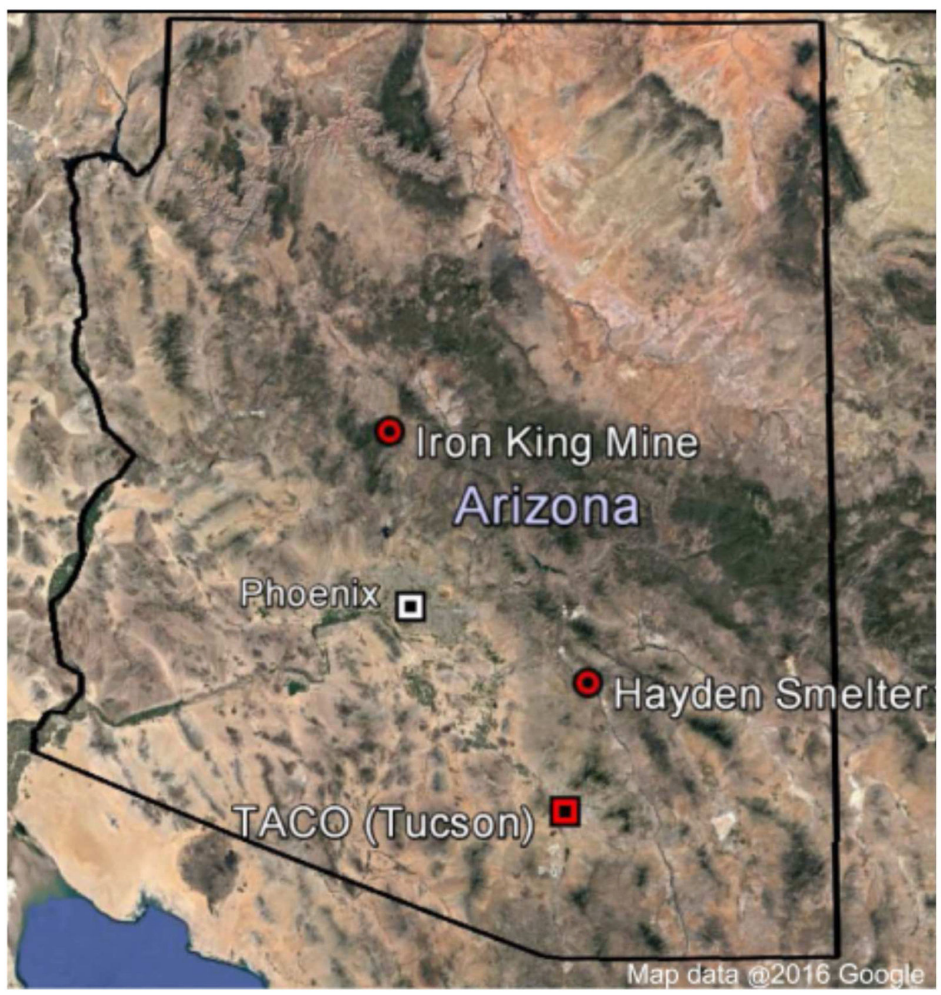

Figure 1.

Map of the study region showing the three measurement sites: (i) Tucson Aerosol Characterization Observation (TACO) in inner-city Tucson, (ii) the active smelting operation at Hayden, and (iii) the legacy mining site at Iron King. 


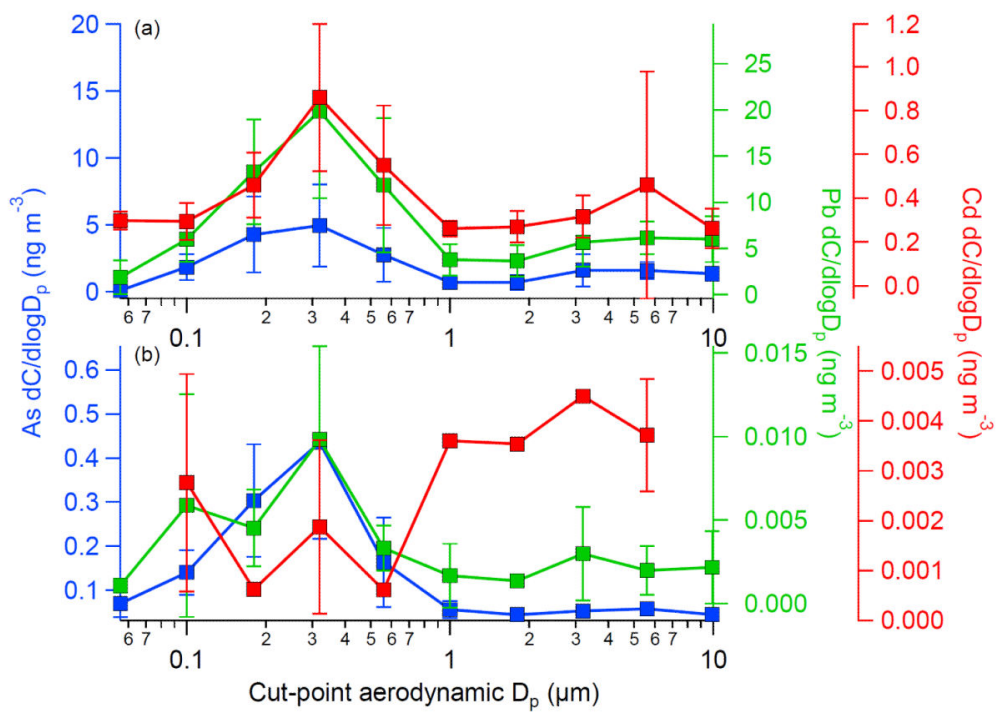

Figure 2.

Average mass size distributions of $\mathrm{Pb}$, As, and $\mathrm{Cd}$ for (a) eight MOUDI sets collected at the Hayden mining operation in the months of August and September in 2009 and (b) five MOUDI sets collected at TACO. Error bars signify one standard deviation and markers without bars indicate only one data point used in the calculation. 

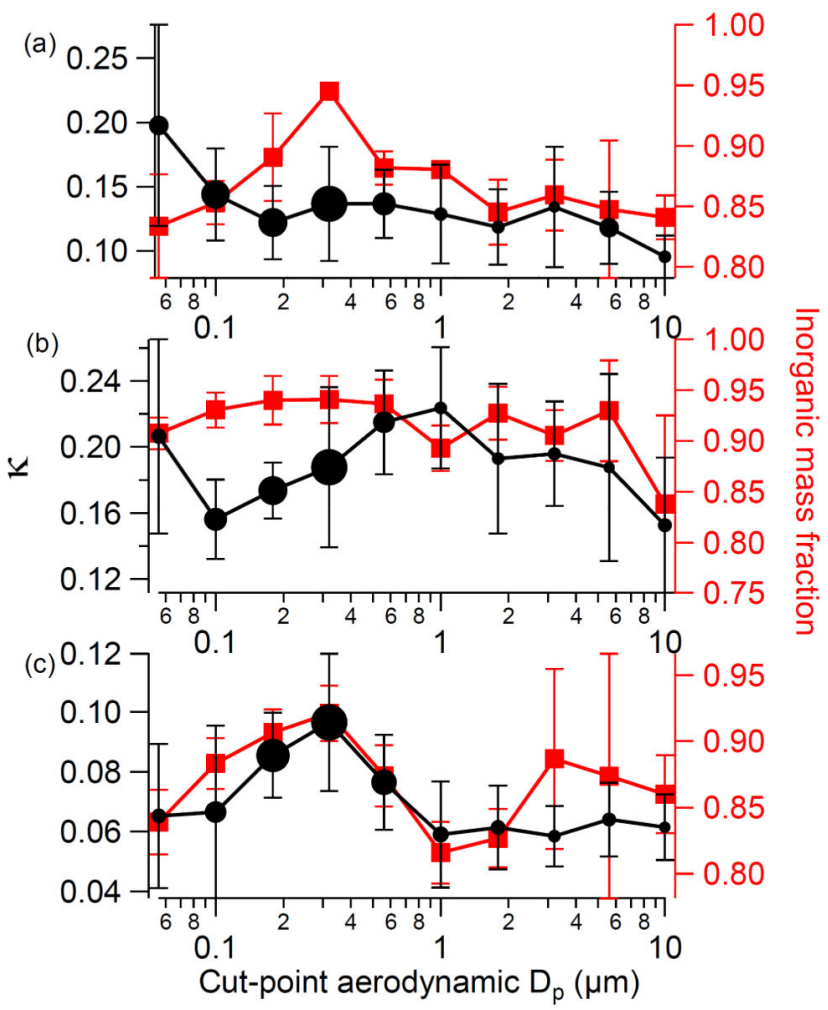

Figure 3.

Single hygroscopicity parameter $\kappa$ and inorganic mass fraction as a function of aerodynamic cut-point diameter for (a) Hayden, (b) Iron King, and (c) TACO. Black marker sizes are proportional to sulfate mass fraction (range: 0.04-0.44) 

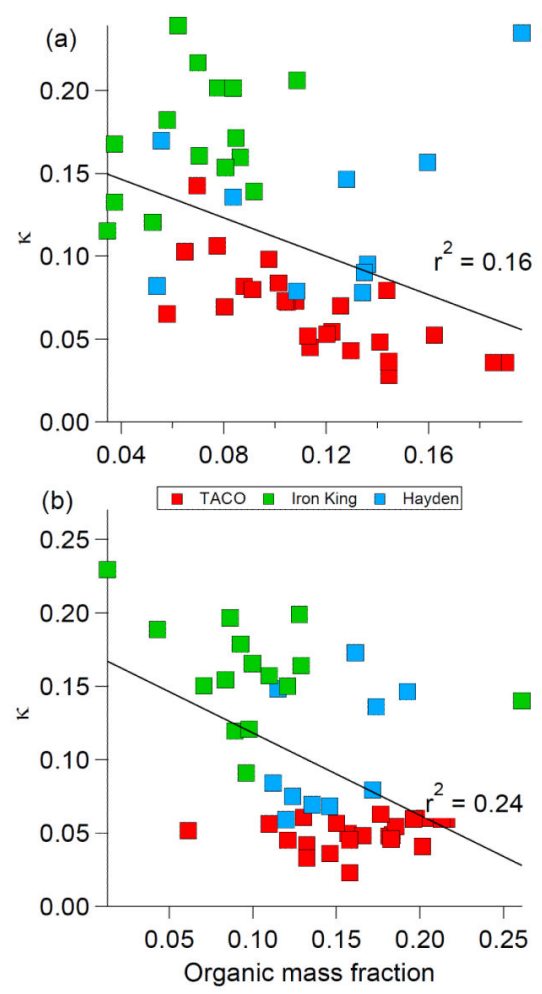

Figure 4.

A comparison of $x$ and organic mass fraction for (a) sub- and (b) super-micrometer aerosol at the three measurement sites. The linear best-fit lines have their corresponding $\mathrm{r}^{2}$ values shown, representing 50 data points for each panel. 


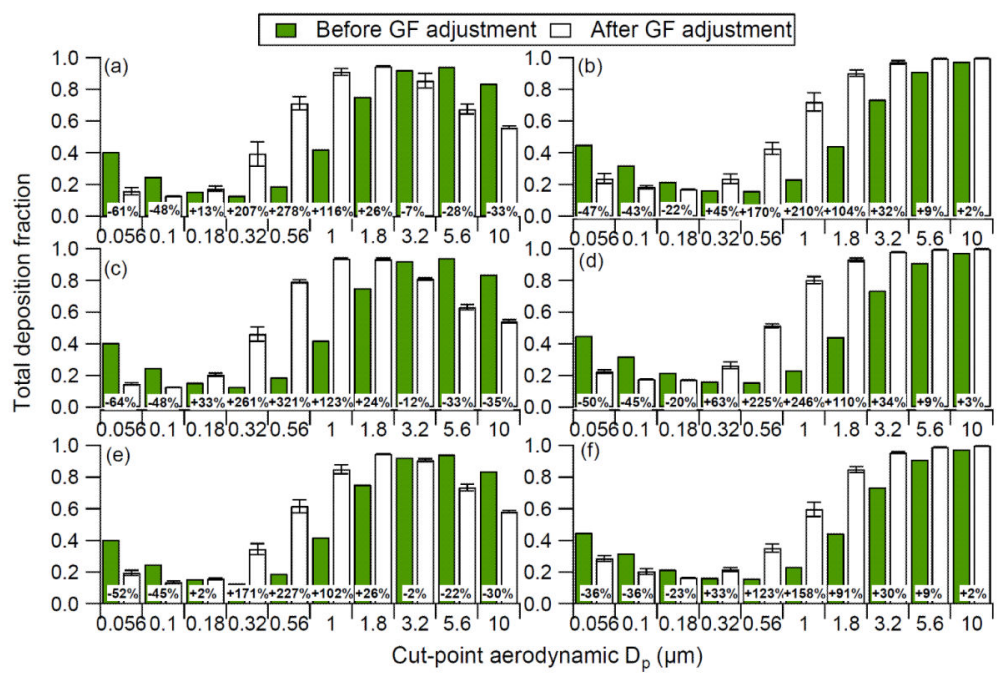

Figure 5.

Comparison of total deposition fraction between dry and humidified particles based on hygroscopicity data collected at (a-b) Hayden, (c-d) Iron King, (e-f) TACO. Panels a/c/e show ICRP results and panels $\mathrm{b} / \mathrm{d} / \mathrm{f}$ show MPPD results. The percent values shown signify the percent change in deposition fraction after accounting for hygroscopic growth. 


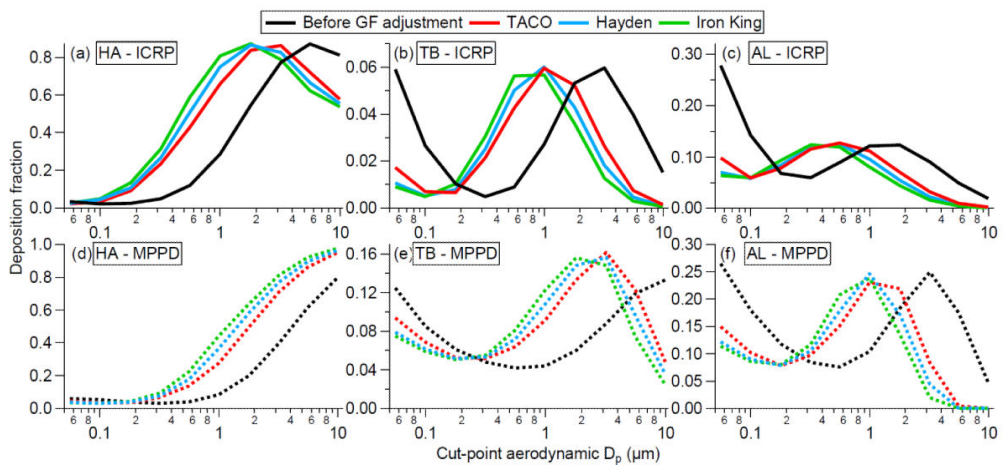

Figure 6.

Regional deposition fraction in different airway regions: (a/d) Head Airways (HA), (b/e) Tracheobronchial (TB), (c/f) Alveolar (AL). Panels a-c and d-f show ICRP and MPPD results, respectively. 


\section{Table 1}

Sampling details for each MOUDI set collected in the study region shown in Figure 1.

\begin{tabular}{cccccc} 
ID & Site & Start Date & End Date & Total Hours & Flow Rate (LPM) \\
\hline IK 1 & Iron King & $10 / 24 / 2011$ & $10 / 28 / 2011$ & 96 & 30 \\
IK 2 & Iron King & $10 / 14 / 2014$ & $10 / 21 / 2014$ & 84 & 30 \\
IK 3 & Iron King & $10 / 21 / 2014$ & $10 / 30 / 2014$ & 108 & 30 \\
H 1 & Hayden & $11 / 15 / 2011$ & $11 / 19 / 2011$ & 96 & 30 \\
H 2 & Hayden & $8 / 30 / 2012$ & $9 / 3 / 2012$ & 81.7 & 30 \\
TACO 1 & TACO & $8 / 19 / 2013$ & $8 / 23 / 2013$ & 96 & 26.5 \\
TACO 2 & TACO & $8 / 26 / 2013$ & $8 / 30 / 2013$ & 96 & 26.3 \\
TACO 3 & TACO & $9 / 3 / 2013$ & $9 / 7 / 2013$ & 96 & 27.0 \\
TACO 4 & TACO & $9 / 9 / 2013$ & $9 / 13 / 2013$ & 96 & 26.8 \\
TACO 5 & TACO & $9 / 16 / 2013$ & $9 / 20 / 2013$ & 97 & 26.5 \\
\hline
\end{tabular}

